\title{
Use of enhanced interleukin-2 formulations for improved immunotherapy against cancer
}

Rosalia, Rodney A ; Arenas-Ramirez, Natalia ; Bouchaud, Grégory ; Raeber, Miro E ; Boyman, Onur

\begin{abstract}
The use of interleukin-2 (IL-2) for the stimulation of an effector immune response against metastatic cancer dates back to the early 1980s. Administration of unmodified IL-2, either alone or together with antigen-specific approaches, has resulted in remarkably long-term survival of some patients suffering from metastatic melanoma. However, such treatment is usually hampered by the appearance of toxic adverse effects, which has motivated the engineering of modified IL-2 formulations showing reduced toxicity while being more potent at stimulating anti-tumor effector immune cells. In this review we summarize and discuss the features and biological relevance of several enhanced IL-2 formulations, compare these to IL-15-based therapeutics, and try to foreshadow their potential in immunological research and immunotherapy.
\end{abstract}

DOI: https://doi.org/10.1016/j.cbpa.2014.09.006

Posted at the Zurich Open Repository and Archive, University of Zurich

ZORA URL: https://doi.org/10.5167/uzh-105611

Journal Article

Accepted Version

Originally published at:

Rosalia, Rodney A; Arenas-Ramirez, Natalia; Bouchaud, Grégory; Raeber, Miro E; Boyman, Onur (2014). Use of enhanced interleukin-2 formulations for improved immunotherapy against cancer. Current Opinion in Chemical Biology, 23C:39-46.

DOI: https://doi.org/10.1016/j.cbpa.2014.09.006 


\section{Use of enhanced interleukin-2 formulations for improved immunotherapy against cancer}

Rodney A. Rosalia ${ }^{1}$, Natalia Arenas Ramirez ${ }^{1}$, Grégory Bouchaud², Miro E. Raeber ${ }^{1}$, and Onur Boyman ${ }^{1}$

${ }^{1}$ Department of Immunology, University Hospital Zurich, Gloriastrasse 30, 8006 Zurich, Switzerland

${ }^{2}$ Institut National de la Recherche Agronomique (INRA), Rue de la Géraudière, BP 71627 Cedex 03, 44316 Nantes, France

Correspondence to: O.B., onur.boyman@uzh.ch

Running title: IL-2 immunotherapy of cancer 


\section{Abstract}

The use of interleukin-2 (IL-2) for the stimulation of an effector immune response against metastatic cancer dates back to the early 1980s. Administration of unmodified IL-2, either alone or together with antigen-specific approaches, has resulted in remarkably long-term survival of some patients suffering from metastatic melanoma. However, such treatment is usually hampered by the appearance of toxic adverse effects, which has motivated the engineering of modified IL-2 formulations showing reduced toxicity while being more potent at stimulating anti-tumor effector immune cells. In this review we summarize and discuss the features and biological relevance of several enhanced IL-2 formulations, compare these to IL-15-based therapeutics, and try to foreshadow their potential in immunological research and immunotherapy. 


\section{Introduction}

Interleukin-2 (IL-2) is a small $15.5 \mathrm{kDa}$ four $\alpha$-helical bundle cytokine, which plays crucial roles both during the resting and activated states of the immune system [1]. The main function of IL-2 during steady-state conditions appears to lie in the development and survival of $\mathrm{CD}^{+}$forkhead box p3 $(\mathrm{Foxp} 3)^{+}$regulatory T-cells (Tregs), thus governing peripheral immune tolerance [2]. Conversely, during an immune response, IL-2 acts as a 'growth factor' of effector immune cells by supporting the proliferation and expansion of effector and memory T-cells and natural killer (NK) cells, and also enhances effector functions of these cells [1-3].

IL-2 can bind to three different IL-2 receptors (IL-2R): IL-2R $\alpha$ (CD25) alone, a heterodimer of IL-2R $\beta$ (CD122) and IL-2R $\gamma$ (also referred to as common $\gamma$-chain receptor, $\gamma \mathrm{c}$ ), and a heterotrimer of CD25, CD122 and $\gamma \mathrm{c}$, which are called the low-, intermediate-, and high-affinity IL-2R, respectively (Figure 1A). CD122 and $\gamma \mathrm{c}$ are crucial for signaling upon IL-2 binding, whereas CD25 does not appear to signal but increases receptor affinity $[3,4]$.

While $\gamma c$ expression remains rather stable, CD25 is up-regulated on recently activated T-cells, along with a moderate elevation of CD122, thereby leading to increased sensitivity of these cells to autocrine and paracrine IL-2. On resting immune cells, CD25 is mainly confined to Tregs, which also express the other IL-2R subunits, thus showing high sensitivity to IL-2. Recently antigen-stimulated T-cells express CD25 mirroring their high dependency on IL-2 during the expansion phase $[3,5]$. Interestingly, during later stages of an immune response, antigen-experienced (memory) CD8 ${ }^{+} \mathrm{T}$-cells and NK cells express very high levels of CD122 (higher than on Tregs) along with $\gamma \mathrm{c}$ and are thus able to compete with Tregs for IL-2 [6,7]. 
IL-2 is a secreted primarily by activated $\mathrm{CD} 4^{+} \mathrm{T}$-cells, but also $\mathrm{CD} 8^{+} \mathrm{T}$-cells, NK and NKT-cells, DCs, and mast cells are able to produce IL-2 following activation $[1,2,8]$.

Owing to its potent T-cell growth-stimulating properties, IL-2 administration has been successfully used since the early 1980 s as a cancer immunotherapy [9-11]. There, IL-2 proved beneficial in patients with end-stage metastatic melanoma or renal cell carcinoma (Figure 2), especially when given as high-dose (HD) IL-2 consisting of 600 '000-720'000 international units per kg body weight per infusion, administered every 8 hours for a maximum of 14 doses $[9,11]$. However, the widespread use of IL2 is hampered by dose-dependent adverse effects, such as hypotension, pulmonary edema, liver cell damage and renal failure. Pathophysiologically, these phenomena appear to result from increased vascular permeability leading to vascular leak syndrome (VLS) [12,13].

Another complicating factor is that IL-2 has a short half-life of 20-30 minutes in the blood in vivo, as it is rapidly cleared by the renal system upon intravenous (iv) injection [12,14,15]. Moreover, HD IL-2 expands Tregs, which can suppress tumorspecific effector $\mathrm{CD} 8^{+} \mathrm{T}$-cell responses $[16,17]$.

Several strategies have been employed to optimize the efficacy of IL-2 for tumor immunotherapy. These include the use of particular anti-IL-2 monoclonal antibodies (mAb), which bind recombinant or endogenous IL-2 and form so-called IL2/anti-IL-2 mAb complexes (IL-2-cx), thereby preferentially directing IL-2 to immune cells expressing high levels of CD122. Other strategies encompass the introduction of specific mutations to IL-2 (IL-2 muteins) to favor binding to either CD25 or CD122, i.e. dimeric or trimeric IL-2Rs, thus preferentially stimulating certain immune cell subsets. Alternatively, IL-2 has been linked to mAbs specific for tumor bed or tumor vasculature thereby generating so-called IL-2 fusion proteins (IL-2-FP) (Table 1). 
In this review, we discuss recent developments in IL-2 tumor immunotherapy by focusing on IL-2-based compounds with improved in vivo properties, and compare these strategies to alternative therapeutics targeting IL-2R subunits, such as IL-15based approaches.

\section{IL-2/anti-IL-2 mAb complexes}

IL-2-cx are generated by the association of murine or human IL-2 with specific mAbs (such as clone S4B6 for murine IL-2), whereby the mAb directs IL-2 to cells expressing high levels of CD122 (in addition to $\gamma \mathrm{c}$ ), including memory CD8 ${ }^{+} \mathrm{T}$-cells and NK cells (Figure 1B) [6]. Use of murine or human IL-2-cx in one or more treatment cycles consisting of 3-7 daily injections induced robust expansion of CD8 ${ }^{+}$ T-cells by $20-100$ fold and of NK cells by $20-30$ fold in vivo $[6,18]$, which translated into significant anti-tumor immune responses and inhibition of tumor growth in several mouse models $[15,18,19]$. IL-2-cx immunotherapy show several advantages over HD IL-2, such as prolonged in vivo half-life, preferential stimulation of effector T-cells over Tregs, and reduction of IL-2-related toxic adverse effects (Table 1) $[6,18,20]$. While the process of complexing IL-2 with a specific anti-IL-2 mAb is rather simple, the complete dissociation of IL-2 from the mAb can be avoided by introducing a flexible linker between IL-2 and the mAb [21].

With the production of humanized or fully human anti-human IL-2 mAbs and the generation of single-molecule IL-2-cx, this technology might soon become available for testing in the clinic. 


\section{IL-2 muteins}

Other strategies have focused on mutated forms of IL-2 (IL-2 muteins). While some IL-2 muteins were designed to target dimeric IL-2Rs, hence leading to the preferential stimulation of memory $\mathrm{CD}^{+} \mathrm{T}$-cells and NK cells, other IL-2 muteins favor cells expressing high levels of CD25, such as recently-activated T-cells, but also Tregs, the latter of which was less obvious when these molecules were engineered (Table 1).

The mutein 'IL-2 superkine' was generated by several amino acid substitutions between positions 80 and 92 of IL-2 [19]. Notably, a change of leucine for valine at position 85 (L85V) resulted in a 5.7-fold increase of affinity for CD122, whereas a set of four additional mutations (L80F, R81D, I86V and I92F) led to an additional 35-fold increase, resulting in an overall increase of affinity for CD122 of about 200-fold over wild-type IL-2. IL-2 superkine was shown to bind IL-2Rs with high affinity in a CD25independent manner. Compared to wild-type IL-2, IL-2 superkine exerted superior anti-tumor properties in different murine tumor models, being comparable to CD122targeting IL-2-cx when using a brief treatment course of five daily injections. However, compared to IL-2-cx, the anti-tumor efficacy of IL-2 superkine was weaker and could not be significantly improved by repetitive treatment cycles or formulation of an IL-2 superkine-Fc construct with longer in vivo activity (unpublished data). As for toxic adverse effects, IL-2 superkine showed, similar to IL-2-cx, reduced IL-2related pulmonary edema and liver cell damage.

With the aim of reducing the affinity of IL-2 to CD25, another IL-2 mutein (termed 'no- $\alpha$ mutein') was generated by introducing an alanine at positions R38, $\mathrm{F} 42$, $\mathrm{Y} 45$, and $\mathrm{E} 62$, resulting in decreased affinity for $\mathrm{CD} 25$ while maintaining normal binding with IL-2R $\beta \gamma$ [22]. No- $\alpha$ mutein inhibited, in an NK-cell dependent manner, the metastasis of the B16 melanoma-variant MB16F0 and of 3LL-D122 Lewis lung 
carcinoma in mice, while exerting lower toxic adverse effects compared to wild-type IL-2. The latter aspect was also confirmed by us using the F42A mutant of IL-2 that displays lower affinity to CD25, which was better tolerated in terms of pulmonary edema than wild-type IL-2 ([19], and unpublished data).

Another research group formulated various IL-2 muteins displaying higher affinity to CD25. In vitro, these IL-2 muteins showed superior capacity to stimulate CD25-expressing KIT-225 cells [23]. In vivo toxicity of these IL-2 muteins was not assessed, however, based on the dependency of IL-2-mediated adverse effects on CD25 [18], we expect to observe similar, or maybe increased, toxicity with CD25directed IL-2 muteins compared to IL-2. Moreover, administration of CD25-directed IL-2 muteins will likely result in significant expansion of Tregs, as is the case with other CD25-directed IL-2 formulations in mice $[6,18]$ and with wild-type IL-2 in humans [24]. Notably, BAY $50-4798$ is a CD25-directed human IL-2 mutein, containing the amino acid substitution N88R, thereby disfavoring binding to CD122 by about 225,000 -fold [25]. The rationale for generating BAY 50-4798 was to reduce IL-2 binding to NK cells, thereby decreasing NK-cell-derived pro-inflammatory cytokines contributing to VLS [26]. However, the clinical response rate following BAY 50-4798 was low: only two out of 45 patients (4\%; one renal cell carcinoma and one metastatic melanoma patient) receiving BAY 50-4798 experienced a partial response. Administration of BAY 50-4798 to patients increased counts of CD4 ${ }^{+} \mathrm{CD} 25^{+}$ T-cells, including Tregs, while $\mathrm{CD}^{+}$T-cell and NK-cell counts changed only minimally [27].

These results show that administration of CD25-directed IL-2 formulations leads to preferential stimulation of $\mathrm{CD}_{2} 5^{+}$Tregs. However, CD25-directed IL-2 formulations might be suitable when combined with antigen-specific cancer vaccines by boosting the expansion of recently-primed - and thus $\mathrm{CD}_{2} 5^{+}[3,5]$ - tumor antigen- 
specific T-cells [15]. Yet, this approach might program T-cells to become short-lived effectors rather than memory cells, the latter of which receive lower intensity IL-2 signals during their expansion phase and depend on CD122-mediated survival signals during memory [1].

Comparing IL-2 muteins to IL-2-cx and wild-type IL-2, IL-2 muteins show similar pharmacokinetic properties as wild-type IL-2, such as a short in vivo half-life [14], and will thus require frequent administration to maintain therapeutic levels (Table 2). IL-2-cx do not possess this disadvantage because of their prolonged halflife [20]. Moreover, IL-2 muteins contain a potentially immunogenic neoepitope, targeting of which might lead to abrogation of its biological activity. In line with this, $27 \%$ of patients developed BAY $50-4798$-specific antibodies already after one round of treatment [27]. Conversely, conventional IL-2-cx consist of two components able to fully dissociate from each other, unless they are associated by a covalent linker [21].

\section{IL-2 fusion proteins}

Various IL-2-FPs (also termed IL-2 immunocytokines) have been generated in the past twenty years (reviewed in [28]). IL-2-FPs were devised to deliver the cytokine to the tumor microenvironment thereby increasing the local dose of IL-2 to levels sufficient to stimulate tumor-specific immune cells, while keeping systemic IL-2 levels and toxic adverse effects low. To this end, IL-2 has been fused to different antibodies or antibody fragments targeting tumor-associated antigens [28].

Selectikine is a fully humanized IL-2-FP developed for the treatment of solid tumors and B-cell non-Hodgkin lymphoma [29-31]. Selectikine comprises mAb NHS76 recognizing single or double-stranded DNA (often released from dying tumor cells) and a CD25-directed IL-2 mutein with a D20T mutation aimed at disrupting a three-amino-acid-sequence motif in IL-2, which appears to be responsible for IL-2- 
binding to endothelial cells, thereby causing endothelial cell damage and VLS [32]. Compared to IL-2, Selectikine induced only mild (grade 1) hypotension and VLS suggesting improved tolerability [31]. Selectikine monotherapy stabilized disease for more than 6 weeks in 23\% (9/39) and combined with low-dose cyclophosphamide in $33 \%(3 / 9)$ of patients with metastatic or local advanced tumors (mostly carcinomas) refractory to standard treatments [30]. Despite the transient increase of total leukocyte, lymphocyte and monocyte counts after each infusion, treatment with Selectikine failed to expand tumor-specific $\mathrm{CD} 8^{+} \mathrm{T}$-cells or promote their effector functions. Notably, circulating Tregs were massively expanded upon Selectikine, however, no correlation existed between blood Treg numbers and overall survival, although intratumoral Tregs were not assessed.

Two other IL-2-FPs (termed GA504 and GA501) consist of an IL-2 mutein with abolished binding to CD25 fused to humanized mAbs targeting carcinoembryonic antigen (CEA). GAS504, given three times weekly, has been reported to strongly expand and activate $\mathrm{NK}$ cells, $\mathrm{CD} 8^{+} \mathrm{T}$-cells and $\gamma \delta \mathrm{T}$-cells and lead to favorable ratios of $\mathrm{CD}^{+}$to $\mathrm{CD} 4^{+} \mathrm{T}$-cells in blood, lymphoid organs and the tumor site. GA504 and GA501 were more efficient in controlling tumor growth of the syngeneic MC38-CEA and PancO2-CEA murine tumors compared to non-targeted IL-2-FP or wild-type IL-2 $[33,34]$.

Another IL-2-FP undergoing clinical testing is hu14.18-IL-2. This immunocytokine is made of wild-type human IL-2 linked to each IgG heavy chain of the hu14.18 mAb, which recognizes disialoganglioside on tumors of neuroectodermal origin, such as neuroblastoma and melanoma [35]. In a phase II clinical trial, fourteen patients received at least two treatment cycles of hu14.18-IL-2, resulting in one partial response (7.1\%) [36]. Subsequently, intratumoral administration of hu14.18IL-2, instead of iv, was tested in the murine NXS2 neuroblastoma model, leading to 
increased intratumoral infiltration of $\mathrm{NK}$ cells and $\mathrm{CD} 8^{+} \mathrm{T}$-cells and improved antitumor effects [37]. However, intratumoral administration might limit the application of hu14.18-IL-2 to patients with solid tumors accessible for injection.

Interestingly, intratumoral administration was shown to induce also systemic immune responses as demonstrated recently using L19-IL2, an IL-2-FP binding the alternatively spliced extra-domain B of fibronectin [38]. Twenty-five patients received once weekly ten million IL-2 international-unit equivalents of L19-IL2 with all lesions visible at screening being injected. Treatment resulted in an objective responses rate of $53.9 \%$ with 6 patients (25\%) experiencing a complete disappearance of all treated lesions. Administration of L19-IL2 led to a transient increase of peripheral Tregs and NK cells, while lowering the numbers of myeloid-derived suppressor cells in blood. Toxic adverse effects were comparable to wild-type IL-2.

Another example of the potent therapeutic effects induced by targeting IL-2 to blood vessels was shown by administration of F16-IL2 and cytarabine to a patient with disseminated extramedullary acute myeloid leukemia [39].

\section{IL-15-based immunotherapeutics}

IL-15 shares many similarities to IL-2 as it also binds to CD122 and $\gamma \mathrm{c}$. However, instead of CD25, IL-15 interacts with high affinity $\left(\mathrm{Kd} \approx 10^{-11} \mathrm{M}\right)$ with its private $\alpha$ chain, termed IL-15R $\alpha$ or CD215. IL-15 signaling is facilitated via cis or transpresentation of IL-15 by IL-15R $\alpha$ [40]. Unlike IL-2, IL-15 minimally stimulates CD25+ Tregs and causes less CD25-mediated toxicity, while efficiently activating CD8 ${ }^{+} \mathrm{T}$ cells and NK cells [7]. We assessed IL-15 and several IL-15-based formulations with extended in vivo half-lives in comparison to IL-2 and IL-2-cx. IL-15-based formulations included complexes of IL-15 with recombinant IL-15R $\alpha$ linked to Fc (IL- 
15/IL-15R $\alpha-F c)$, IL-15/anti-IL-15 mAb complexes, and IL-15 coupled covalently via a linker to IL-15R $\alpha$ (termed RLI, [41]). IL-2-cx conferred slightly better tumor control against subcutaneous B16F10 melanoma than the IL-15-based formulations, and both groups of formulations largely surpassed IL-2 and IL-15 for anti-tumor efficacy. This effect was paralleled by $\mathrm{CD} 8^{+} \mathrm{T}$-cell expansion. Interestingly, modest Treg expansion occurred following IL-2-cx but also IL-15 formulations, with the latter also appearing to affect myeloid-derived cell subsets (unpublished data). In line with our observations, the potential for clinical application of IL-15 formulations for cancer immunotherapy has been shown in B16F10 melanoma and pancreatic cancer in RIP1-Tag2 mice $[42,43]$. Significant reduction in tumor burden and increased survival of mice treated with IL-15-IL-15Ra-FP was observed, while treatment with IL-15 showed a negligible effect in these settings.

\section{Final comments and conclusions}

IL-2 cancer immunotherapy is experiencing a revival thanks to the advent of several IL-2 formulations, especially CD122-directed and tumor-targeting compounds, with superior immune stimulatory properties and robust anti-tumor efficacy in pre-clinical and early clinical situations compared to wild-type IL-2. The majority of these novel IL-2 formulations display significantly reduced toxic adverse effects in comparison to IL-2. While improved IL-2 formulations might be useful as monotherapies, their combination with other anti-cancer immunotherapies, such as adoptive T-cell transfer regimens, antigen-specific vaccination, and blockade of inhibitory molecules, e.g. cytotoxic T-lymphocyte antigen-4 and programmed cell death-1, to expand and maintain efficacious tumor-specific T-cell responses, might hold the promise of controlling metastatic cancer. 


\section{Acknowledgements}

We thank the members of the Boyman laboratory for critical reading of the manuscript. This work was funded by Swiss Cancer League grants KFS-02672-08-2010, SNF grants PP00P3128421 and CRSII3-136203 (all to O.B.).

Conflict-of-interest disclosure: The authors declare no competing financial interests. 
A
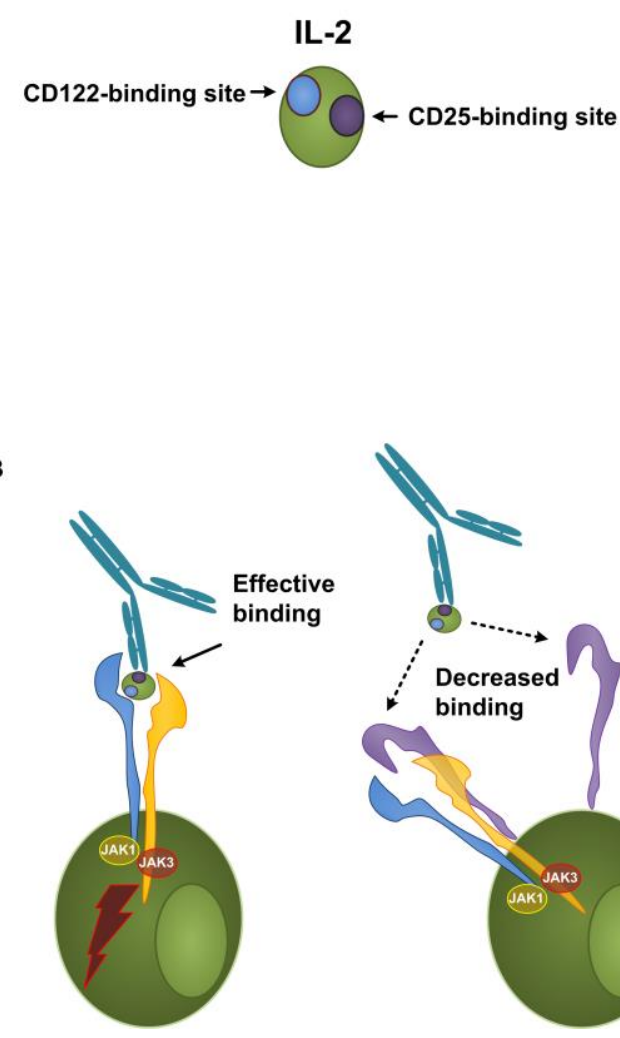

Low-affinity monomeric $\operatorname{IL}-2 \operatorname{R} \alpha\left(\mathrm{K}_{\mathrm{d}} \approx 10^{-8} \mathrm{M}\right)$

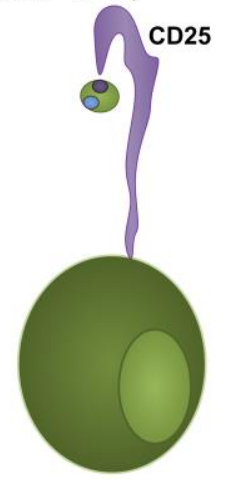

Intermediate-affinity dimeric $\operatorname{IL}-2 \mathrm{R} \beta \gamma\left(\mathrm{K}_{\mathrm{d}} \approx 10^{-9} \mathrm{M}\right)$

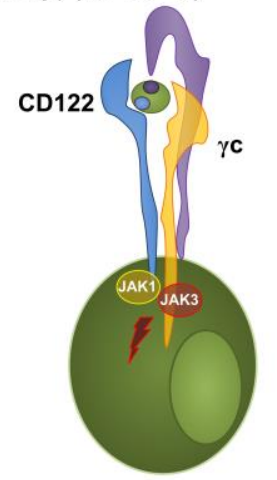

High-affinity trimeric

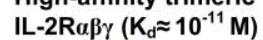

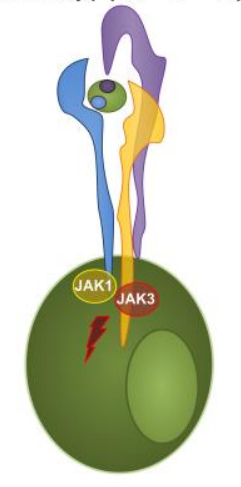

Figure 1. Properties of different IL-2 receptors and CD122-directed IL-2-CX. (A) IL-2 can be bound by CD25 (also known as IL-2 receptor $\alpha, \mathrm{IL}-2 \mathrm{R} \alpha$ ) alone, a heterodimer of CD122 (IL-2R $\beta$ ) and $\gamma \mathrm{c}$ (common $\gamma$-chain receptor or alternatively known as IL-2R $\gamma$ ), or a heterotrimer of CD25, CD122 and $\gamma \mathrm{C}$. CD122 and $\gamma \mathrm{C}$ are able to signal, whereas CD25 increases IL-2R affinity $[1,2,4,8]$. (B) Preferential stimulation of cells expressing high levels of CD122 is achieved by complexing IL-2 with a particular anti-IL-2 mAb (such as clone S4B6 for murine IL-2), which binds IL-2 at a site within or neighboring the CD25-binding site thus impairing binding to CD25 and trimeric IL-2Rs $[1,6,20]$. 


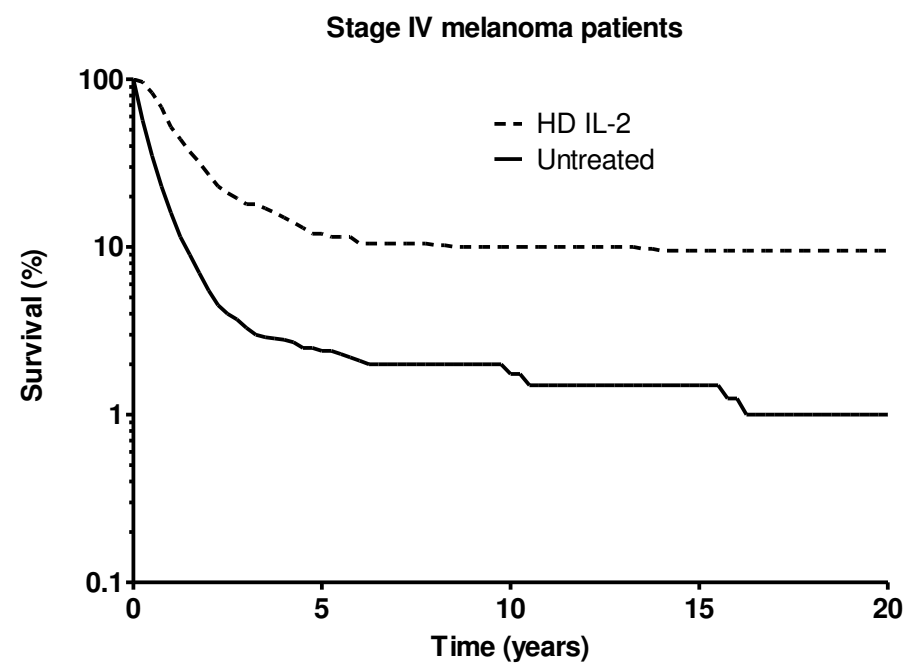

Figure 2. Overall survival of stage IV melanoma patients with or without high-dose IL2 treatment. Shown are survival data of untreated patients with stage IV melanoma and of stage IV melanoma patients following high-dose (HD) IL-2 immunotherapy, adapted from [44] and [10], respectively. 
Table 1. Biochemical, pharmacological and immunological properties of IL-2 formulations compared to IL-15 compounds.

\begin{tabular}{|c|c|c|c|c|c|c|c|}
\hline Compound & $\begin{array}{l}\text { Binding to } \\
\text { CD25 }\end{array}$ & $\begin{array}{l}\text { Binding to } \\
\text { CD122 }\end{array}$ & $\begin{array}{c}\text { Stimulation of } \\
\text { CD4 }{ }^{+} \text {CD } 25^{+} \\
\text {Tregs } \\
\end{array}$ & $\begin{array}{l}\text { Stimulation } \\
\text { of } \mathrm{CD}^{+} \mathrm{T} \text { - } \\
\text { cells }\end{array}$ & $\begin{array}{l}\text { Stimulation } \\
\text { of NK cells }\end{array}$ & $\begin{array}{l}\text { Half-life in } \\
\text { blood (hours) }\end{array}$ & Ref. \\
\hline \multicolumn{8}{|l|}{ Wild-type IL-2 } \\
\hline HD IL-2 & ++ & + & +++ & ++ & ++ & $+(0.5-1 \mathrm{~h})$ & {$[9,45]$} \\
\hline LD IL-2 & ++ & + & ++ & + & + & $+(0.5-1 \mathrm{~h})$ & {$[45]$} \\
\hline IL-2-cx & - & + & ++ & ++++ & +++ & $+++(>24 h)$ & {$[15,18]$} \\
\hline \multicolumn{8}{|l|}{ IL-2 muteins } \\
\hline $\begin{array}{l}\text { CD25-directed } \\
\text { IL-2 muteins }\end{array}$ & +++ & + & $+++(\text { in vitro })^{\circ}$ & ND & ND & + & [23] \\
\hline BAY 50-4798 & ++ & - & +++ & + & + & + & {$[25,27]$} \\
\hline IL-2-superkine & ++ & +++ & ++ & +++ & +++ & + & [19] \\
\hline No- $\alpha$ mutein & + & + & + & + & + & + & [22] \\
\hline \multicolumn{8}{|l|}{ IL-2-FPs } \\
\hline hu14.18-IL-2 & ++ & + & ND & ND & ND & $++(2-4 h)$ & {$[46]$} \\
\hline F8-IL2 / F16-IL2 & ++ & + & ND & ND & ND & $+++\#$ & [39] \\
\hline L19-IL2 & ++ & + & ++ & ++ & ++ & +++ & {$[47,48]$} \\
\hline \multicolumn{8}{|l|}{ IL-2-mutein-FPs } \\
\hline Selectikine & ++ & + & +++ & ND & + & $++(5 \mathrm{~h})$ & {$[30,31]$} \\
\hline $\begin{array}{l}\text { CEA-IL2v } \\
\text { (GA504 \& GA501) }\end{array}$ & - & + & $+/++$ & +++ & +++ & $+++\#$ & {$[33,34]$} \\
\hline \multicolumn{8}{|l|}{ IL-15 formulations } \\
\hline IL-15/mAb-cx & - & + & $+/++$ & +++ & +++ & $+++\#$ & UP \\
\hline IL-15/IL-15R $\alpha-C x$ & - & +++ & $+/++$ & +++ & +++ & $+++\#$ & [42] \\
\hline RLI & - & +++ & $+/++$ & +++ & +++ & $++(3 h)$ & {$[41]$} \\
\hline
\end{tabular}

$\mathrm{ND}=$ not determined, UP $=$ unpublished data.

- no effect, + weak, ++ mild, +++ strong, ++++ very strong, compared to control.

${ }^{\circ}$ The human CD25 $5^{+}$KIT-225 T-cell line was used to assess potency of IL-2Ra-targeting muteins [23].

\# Estimated. 
Table 2. Therapeutic anti-tumor properties of IL-2 formulations compared to IL-15 compounds.

\begin{tabular}{|c|c|c|c|c|c|c|c|}
\hline \multirow{3}{*}{ Compound } & \multicolumn{4}{|c|}{ Anti-tumor efficacy } & \multicolumn{2}{|c|}{ Adverse effects } & \multirow{3}{*}{ Ref. } \\
\hline & \multirow{2}{*}{$\begin{array}{c}\text { Pre- } \\
\text { clinical }^{a}\end{array}$} & \multicolumn{3}{|c|}{ Clinical objective response (\%) } & \multirow{2}{*}{ Pre-clinical $^{\text {a }}$} & \multirow{2}{*}{$\begin{array}{c}\text { Clinical } \\
{\text { (grade } 3 \text { and } 4)^{b}}^{b}\end{array}$} & \\
\hline & & $0-0.5$ years & $0.5-5$ years & $>5$ years & & & \\
\hline \multicolumn{8}{|l|}{ Wild-type IL-2 } \\
\hline HD IL-2 & $++^{[18]}$ & $40-48 \%$ & $10-36 \%$ & $8-9.3 \%$ & +++ & $36-45 \% \times$ & {$[9,45]$} \\
\hline LD IL-2 & + & ND & ND & ND & + & $2.9 \% \times$ & [45] \\
\hline IL-2-cx & +++ & ND & ND & ND & + & ND & {$[15,18]$} \\
\hline \multicolumn{8}{|l|}{ IL-2 muteins } \\
\hline $\begin{array}{l}\text { CD25-directed } \\
\text { IL-2 muteins }\end{array}$ & ND & ND & ND & ND & ND & ND & [23] \\
\hline BAY 50-4798 & +++ & $0 \%(0 / 48)$ & ND & ND & + & $70-80 \%$ & {$[25,27]$} \\
\hline IL-2-superkine & $++/+++$ & ND & ND & ND & + & ND & [19] \\
\hline No- $\alpha$ mutein & +++ & ND & ND & ND & + & ND & [22] \\
\hline \multicolumn{8}{|l|}{ IL-2-FPs } \\
\hline hu14.18-IL-2 & $++/+++$ & $0 \%(0 / 9)$ & ND & ND & + & $41 \%$ & {$[46]$} \\
\hline F8-IL2 / F16-IL2 & +++ & $\begin{array}{l}\text { 1/1 (case } \\
\text { study) }\end{array}$ & ND & ND & + & ND & [39] \\
\hline L19-IL2 & +++ & $53.9 \%$ & ND & ND & ND & $10-20 \%$ & {$[47,48]$} \\
\hline \multicolumn{8}{|l|}{ IL-2-mutein-FPs } \\
\hline Selectikine & ++ & $7-14 \%$ & ND & ND & + & $10 \%$ & {$[30,31]$} \\
\hline $\begin{array}{l}\text { CEA-IL2v } \\
\text { (GA504 \& GA501) }\end{array}$ & +++ & ND & ND & ND & ND & ND & {$[33,34]$} \\
\hline \multicolumn{8}{|l|}{ IL-15 formulations } \\
\hline IL-15/mAb-cx & ++ & ND & ND & ND & + & ND & UP \\
\hline IL-15/IL-15R $\alpha-c x$ & $++/+++$ & ND & ND & ND & + & ND & {$[42]$} \\
\hline RLI & $++/+++$ & ND & ND & ND & + & ND & {$[41]$} \\
\hline
\end{tabular}

$\mathrm{ND}=$ not determined, UP $=$ unpublished data; objective responses $=\%$ of complete plus partial response of treated patients, excluding stable disease.

Clinical adverse effects of IL-2 are shown only for grade 3 and 4 reactions, whereby $\left({ }^{\times}\right)$indicates hypotension.

A 98\% humanized version of the hu14.18-IL-2 containing a single point mutation $(K 322 A)$, termed hu14.18K322A showed better objective responses $(6 / 31,20 \%)$ in patients with recurrent neuroblastoma [49]. 


\section{References}

1. Boyman $O$, Sprent J: The role of interleukin-2 during homeostasis and activation of the immune system. Nat Rev Immunol. 2012, 12:180-190. doi: 110.1038/nri3156.

2. Malek TR, Castro I: Interleukin-2 receptor signaling: at the interface between tolerance and immunity. Immunity 2010, 33:153-165.

3. Smith KA: Interleukin-2: inception, impact, and implications. Science 1988, 240:1169-1176.

4. Taniguchi T, Minami Y: The IL-2/IL-2 receptor system: a current overview. Cell 1993, 73:5-8.

5. Rosalia RA, Silva AL, Camps M, Allam A, Jiskoot W, van der Burg SH, Ossendorp F, Oostendorp J: Efficient ex vivo induction of $T$ cells with potent anti-tumor activity by protein antigen encapsulated in nanoparticles. Cancer Immunol Immunother 2013, 62:1161-1173.

6. Boyman $O$, Kovar M, Rubinstein MP, Surh CD, Sprent J: Selective stimulation of $T$ cell subsets with antibody-cytokine immune complexes. Science. 2006, 311:1924-1927. Epub 2006 Feb 1916.

-• Original publication describing the selective stimulation of effector $\mathrm{T}$ cells or $\mathrm{T}$ regulatory cells depending on the antibody used to formulate IL-2/anti-IL-2 antibody immune complexes.

7. Boyman $O$, Krieg C, Homann D, Sprent J: Homeostatic maintenance of $T$ cells and natural killer cells. Cell Mol Life Sci 2012, 69:1597-1608.

8. Liao W, Lin JX, Leonard WJ: Interleukin-2 at the crossroads of effector responses, tolerance, and immunotherapy. Immunity 2013, 38:13-25.

- Review article summarizing the recent insights on the molecular mechanisms and complex cellular actions of IL-2, how IL-2 synergize or antagonize with other cytokines, and finally how IL-2 immunotherapy can be harnessed as a clinical medicine

9. Atkins MB, Lotze MT, Dutcher JP, Fisher RI, Weiss G, Margolin K, Abrams J, Sznol M, Parkinson D, Hawkins $M$, et al.: High-dose recombinant interleukin 2 therapy for patients with metastatic melanoma: analysis of 270 patients treated between 1985 and 1993. J Clin Oncol 1999, 17:2105-2116.

- Publication describing eight clinical trials encompassing a total of 270 melanoma patients treated with high-dose IL-2. This paper is the first to show in a large study population the effective immune stimulatory, toxicities and therapeutic efficacy of IL-2 as a cancer immunotherapy for late-stage melanoma

10. Smith FO, Downey SG, Klapper JA, Yang JC, Sherry RM, Royal RE, Kammula US, Hughes MS, Restifo $N P$, Levy $C L$, et al.: Treatment of metastatic melanoma using interleukin-2 alone or in conjunction with vaccines. Clin Cancer Res. 2008, 14:5610-5618. doi: 5610.1158/10780432.CCR-5608-0116.

11. Klapper JA, Downey SG, Smith FO, Yang JC, Hughes MS, Kammula US, Sherry RM, Royal RE, Steinberg $S M$, Rosenberg S: High-dose interleukin-2 for the treatment of metastatic renal cell carcinoma : a retrospective analysis of response and survival in patients treated in the surgery branch at the National Cancer Institute between 1986 and 2006. Cancer. 2008, 113:293-301. doi: 210.1002/cncr.23552.

-• Publication on a retrospective study analyzing the effectiveness of high-dose IL-2 given to 259 renal cell carcinoma patients showing that IL-2 cancer immunotherapy results in durable clinical responses

12. Boyman $O$, Surh CD, Sprent J: Potential use of IL-2/anti-IL-2 antibody immune complexes for the treatment of cancer and autoimmune disease. Expert Opin Biol Ther 2006, 6:1323-1331.

13. McDermott DF, Atkins MB: Application of IL-2 and other cytokines in renal cancer. Expert Opin Biol Ther 2004, 4:455-468.

14. Donohue $\mathrm{JH}$, Rosenberg SA: The fate of interleukin-2 after in vivo administration. $J$ Immunol 1983, 130:2203-2208.

15. Tomala J, Chmelova H, Mrkvan T, Rihova B, Kovar M: In vivo expansion of activated naive CD8+ T cells and NK cells driven by complexes of IL-2 and anti-IL-2 monoclonal antibody as novel approach of cancer immunotherapy. J Immunol 2009, 183:4904-4912. 
16. Klages K, Mayer CT, Lahl K, Loddenkemper C, Teng MW, Ngiow SF, Smyth MJ, Hamann A, Huehn J, Sparwasser $T$ : Selective depletion of Foxp3+ regulatory $T$ cells improves effective therapeutic vaccination against established melanoma. Cancer Res 2010, 70:7788-7799.

17. Antony PA, Piccirillo CA, Akpinarli A, Finkelstein SE, Speiss PJ, Surman DR, Palmer DC, Chan CC, Klebanoff $C A$, Overwijk $W W$, et al.: CD8+ $T$ cell immunity against a tumor/self-antigen is augmented by $\mathrm{CD} 4+T$ helper cells and hindered by naturally occurring $T$ regulatory cells. J Immunol 2005, 174:2591-2601.

- Original article describing the inhibitory effects of T regulatory cells on tumor/self-antigens in a setting of adoptive T cell immunotherapy. Co-transfer of T helper cells significantly enhanced the effector functions of $\mathrm{CD} 8^{+} \mathrm{T}$ cells whereas co-transfer of $\mathrm{T}$ regulatory cells abrogated anti-tumor immunity.

18. Krieg C, Letourneau S, Pantaleo G, Boyman O: Improved IL-2 immunotherapy by selective stimulation of IL-2 receptors on lymphocytes and endothelial cells. Proc Natl Acad Sci U S A. 2010, 107:11906-11911. doi: 11910.11073/pnas.1002569107. Epub 1002562010 Jun 1002569114.

•• Original paper showing that CD122-directed IL-2/anti-IL-2 antibody immune complexes (IL-2-cx) can be harnessed for a effective cancer immunotherapy. Moreover, the used of such IL-2-cx significantly reduced the onset of IL-2 related adverse effects which was shown to be mediated by preventing binding to $\mathrm{CD} 25^{+}$endothelial cells.

19. Levin AM, Bates DL, Ring AM, Krieg C, Lin JT, Su L, Moraga I, Raeber ME, Bowman GR, Novick P, et al.: Exploiting a natural conformational switch to engineer an interleukin-2 'superkine'. Nature. 2012, 484:529-533. doi: 510.1038/nature10975.

- Original paper describing the formulation of IL-2 mutants with showing a preferential targeting, binding and stimulation of CD122 leading to improved T and NK cell expansion and anti-tumor effects

20. Letourneau S, van Leeuwen EM, Krieg C, Martin C, Pantaleo G, Sprent J, Surh CD, Boyman O: IL2/anti-IL-2 antibody complexes show strong biological activity by avoiding interaction with IL-2 receptor alpha subunit CD25. Proc Natl Acad Sci U S A. 2010, 107:2171-2176. doi: 2110.1073/pnas.0909384107. Epub 0909382010 Jan 0909384119.

21. Tomala J, Kovarova J, Kabesova M, Votavova P, Chmelova H, Dvorakova B, Rihova B, Kovar M: Chimera of IL-2 linked to light chain of anti-IL-2 mAb mimics IL-2/anti-IL-2 mAb complexes both structurally and functionally. ACS Chem Biol 2013, 8:871-876.

- This study elegantly shows that formulating IL-2/anti-IL-2 antibody immune complexes (IL-2-Cx) using a covalent chemical linker between IL-2 and a anti-IL-2 antibody prevents the complete desociation of IL-2 in resulting in IL-2-cx with significantly improved T cell stimulatory capacity compared to non-covalently linked IL-2-cx.

22. Carmenate T, Pacios A, Enamorado M, Moreno E, Garcia-Martinez K, Fuente D, Leon K: Human IL2 mutein with higher antitumor efficacy than wild type IL-2. J Immunol 2013, 190:62306238.

- A study describing the production of an IL-2 mutant with reduced binding to CD25. Treatment using this IL-2 mutant leads to better anti-tumor efficacy compared to wild-type IL-2 in a NK-cell dependent manner.

23. Rao BM, Driver I, Lauffenburger DA, Wittrup KD: High-affinity CD25-binding IL-2 mutants potently stimulate persistent T cell growth. Biochemistry 2005, 44:10696-10701.

24. Ahmadzadeh M, Rosenberg SA: IL-2 administration increases CD4+ CD25(hi) Foxp3+ regulatory $T$ cells in cancer patients. Blood 2006, 107:2409-2414.

25. Shanafelt $A B$, Lin $Y$, Shanafelt $M C$, Forte $C P$, Dubois-Stringfellow N, Carter $C$, Gibbons JA, Cheng SL, Delaria KA, Fleischer $R$, et al.: A T-cell-selective interleukin 2 mutein exhibits potent antitumor activity and is well tolerated in vivo. Nat Biotechnol 2000, 18:1197-1202. 
26. Assier E, Jullien V, Lefort J, Moreau JL, Di Santo JP, Vargaftig BB, Lapa e Silva JR, Theze J: NK cells and polymorphonuclear neutrophils are both critical for IL-2-induced pulmonary vascular leak syndrome. J Immunol 2004, 172:7661-7668.

27. Margolin K, Atkins MB, Dutcher JP, Ernstoff MS, Smith JW, 2nd, Clark JI, Baar J, Sosman J, Weber J, Lathia $C$, et al.: Phase I trial of BAY 50-4798, an interleukin-2-specific agonist in advanced melanoma and renal cancer. Clin Cancer Res 2007, 13:3312-3319.

28. Muller D: Antibody-cytokine fusion proteins for cancer immunotherapy: an update on recent developments. BioDrugs 2014, 28:123-131.

- Review article describing recent developments in the field of immunocytokines for cancer

immunotherapy

29. Gillies SD, Lan Y, Hettmann T, Brunkhorst B, Sun Y, Mueller SO, Lo KM: A low-toxicity IL-2-based immunocytokine retains antitumor activity despite its high degree of IL-2 receptor selectivity. Clin Cancer Res 2011, 17:3673-3685.

30. Laurent J, Touvrey C, Gillessen S, Joffraud M, Vicari M, Bertrand C, Ongarello S, Liedert B, Gallerani $E$, Beck J, et al.: T-cell activation by treatment of cancer patients with EMD 521873 (Selectikine), an IL-2/anti-DNA fusion protein. J Transl Med 2013, 11:5.

31. Gillessen S, Gnad-Vogt US, Gallerani E, Beck J, Sessa C, Omlin A, Mattiacci MR, Liedert B, Kramer $D$, Laurent J, et al.: A phase I dose-escalation study of the immunocytokine EMD 521873 (Selectikine) in patients with advanced solid tumours. Eur J Cancer 2013, 49:35-44.

32. Baluna R, Rizo J, Gordon BE, Ghetie V, Vitetta ES: Evidence for a structural motif in toxins and interleukin-2 that may be responsible for binding to endothelial cells and initiating vascular leak syndrome. Proc Natl Acad Sci U S A 1999, 96:3957-3962.

33. Klein C: S41. Novel CEA-targeted IL2 variant immunocytokine for immunotherapy of cancer. Journal for ImmunoTherapy of Cancer 2014, 2:18.

34. Klein C, Waldhauer I, Nicolini V, Dunn C, Freimoser-Grundschober A, Herter S, Geven E, Boerman $O$, Nayak T, van Puijenbroek $E$, et al.: Abstract 486: Tumor-targeted, engineered IL-2 variant (IL-2v)-based immunocytokines for the immunotherapy of cancer. Cancer Research 2013, 73:486.

35. Becker JC, Pancook JD, Gillies SD, Furukawa K, Reisfeld RA: T cell-mediated eradication of murine metastatic melanoma induced by targeted interleukin 2 therapy. J Exp Med 1996, 183:23612366.

36. Albertini MR, Hank JA, Gadbaw B, Kostlevy J, Haldeman J, Schalch H, Gan J, Kim K, Eickhoff J, Gillies SD, et al.: Phase II trial of hu14.18-IL2 for patients with metastatic melanoma. Cancer Immunol Immunother 2012, 61:2261-2271.

37. Yang RK, Kalogriopoulos NA, Rakhmilevich AL, Ranheim EA, Seo S, Kim K, Alderson KL, Gan J, Reisfeld RA, Gillies $S D$, et al.: Intratumoral treatment of smaller mouse neuroblastoma tumors with a recombinant protein consisting of IL-2 linked to the hu14.18 antibody increases intratumoral CD8+ $T$ and $N K$ cells and improves survival. Cancer Immunol Immunother 2013, 62:1303-1313.

- This study assesses the advantages of intratumoral delivery of an immunocytikine in comparison to the conventional systemic administration. The authors elegantly show that intratumoral delivery promotes the infiltration of tumor-specific effector cells leading to better survival.

38. Weide B, Eigentler TK, Pflugfelder A, Zelba H, Martens A, Pawelec G, Giovannoni L, Ruffini PA, Elia $G$, Neri $D$, et al.: Intralesional Treatment of Stage III Metastatic Melanoma Patients with L19-IL2 Results in Sustained Clinical and Systemic Immunologic Responses. Cancer Immunol Res 2014.

39. Gutbrodt KL, Schliemann C, Giovannoni L, Frey K, Pabst T, Klapper W, Berdel WE, Neri D: Antibody-based delivery of interleukin-2 to neovasculature has potent activity against acute myeloid leukemia. Sci Transl Med 2013, 5:201ra118.

- In this article, the potent effects of tumor-related neovasculature targeting of an immunocytikine is described. In addition, effective cancer immunotherapy through neovasculatore targeting is described for single case study with a AML patient. 
40. Dubois S, Mariner J, Waldmann TA, Tagaya Y: IL-15Ralpha recycles and presents IL-15 In trans to neighboring cells. Immunity 2002, 17:537-547.

41. Bessard A, Sole V, Bouchaud G, Quemener A, Jacques Y: High antitumor activity of RLI, an interleukin-15 (IL-15)-IL-15 receptor alpha fusion protein, in metastatic melanoma and colorectal cancer. Mol Cancer Ther 2009, 8:2736-2745.

42. Dubois S, Patel HJ, Zhang M, Waldmann TA, Muller JR: Preassociation of IL-15 with IL-15R alphaIgG1-Fc enhances its activity on proliferation of NK and CD8+/CD44high $T$ cells and its antitumor action. J Immunol 2008, 180:2099-2106.

43. Epardaud $M$, Elpek KG, Rubinstein MP, Yonekura AR, Bellemare-Pelletier A, Bronson R, Hamerman $J A$, Goldrath $A W$, Turley SJ: Interleukin-15/interleukin-15R alpha complexes promote destruction of established tumors by reviving tumor-resident CD8+ T cells. Cancer Res 2008, 68:2972-2983.

-• Authors present data on the use of IL-15/L-15Ra complexes to rescue the effector functions of tumor-resident $\mathrm{T}$ cells and discuss the implications of these compound as a novel cancer

immunotherapy.

44. Haffner AC, Garbe C, Burg G, Buttner P, Orfanos CE, Rassner G: The prognosis of primary and metastasising melanoma. An evaluation of the TNM classification in 2,495 patients. $\mathrm{Br} J$ Cancer 1992, 66:856-861.

45. Yang JC, Sherry RM, Steinberg SM, Topalian SL, Schwartzentruber DJ, Hwu P, Seipp CA, RogersFreezer $L$, Morton KE, White $D E$, et al.: Randomized study of high-dose and low-dose interleukin-2 in patients with metastatic renal cancer. J Clin Oncol 2003, 21:3127-3132.

46. Shusterman $S$, London WB, Gillies $S D$, Hank $J A$, Voss $S D$, Seeger RC, Reynolds $C P$, Kimball J, Albertini MR, Wagner $B$, et al.: Antitumor activity of hu14.18-IL2 in patients with relapsed/refractory neuroblastoma: a Children's Oncology Group (COG) phase II study. J Clin Oncol 2010, 28:4969-4975.

47. Johannsen M, Spitaleri G, Curigliano G, Roigas J, Weikert S, Kempkensteffen C, Roemer A, Kloeters $C$, Rogalla $P$, Pecher $G$, et al.: The tumour-targeting human L19-IL2 immunocytokine: preclinical safety studies, phase I clinical trial in patients with solid tumours and expansion into patients with advanced renal cell carcinoma. Eur J Cancer 2010, 46:2926-2935.

48. Carnemolla B, Borsi L, Balza E, Castellani P, Meazza R, Berndt A, Ferrini S, Kosmehl H, Neri D, Zardi $L$ : Enhancement of the antitumor properties of interleukin-2 by its targeted delivery to the tumor blood vessel extracellular matrix. Blood 2002, 99:1659-1665.

49. Navid F, Sondel PM, Barfield R, Shulkin BL, Kaufman RA, Allay JA, Gan J, Hutson P, Seo S, Kim K, et al.: Phase I trial of a novel anti-GD2 monoclonal antibody, Hu14.18K322A, designed to decrease toxicity in children with refractory or recurrent neuroblastoma. J Clin Oncol 2014, 32:1445-1452.

- This study shows that the abrogation of complement activation by an immunocytikine greatly improves clinical efficacy while reducing the onset of adverse effects. 


\section{Highlights}

- IL-2 immunotherapy can induce durable tumor regression of metastatic cancer.

- IL-2 can lead to toxic adverse effects and stimulate regulatory $\mathrm{CD} 4^{+} \mathrm{T}$ cells.

- Compared to IL-2, CD122-directed IL-2 formulations show a better therapeutic profile.

- CD122-directed formulations include IL-2/anti-IL-2 mAb complexes and IL-2 muteins. 